https://doi.org/10.15407/ujpe65.1.75

O.I. ZAVALISTYI, O.V. MAKARENKO, V.A. ODARYCH, A.L. YAMPOLSKIY

Taras Shevchenko National University of Kyiv, Faculty of Physics, Department of Optics (64/13, Volodymyrs'ka Str., Kyiv 01601, Ukraine)

\title{
THE STRUCTURE OF OXIDE FILM ON THE POROUS SILICON SURFACE
}

\begin{abstract}
A prolonged stay of porous silicon in the air environment gives rise to structural changes in its surface layer, and the standard single-layer model is not sufficiently accurate to describe them. In this work, the structure of the near-surface layer in porous silicon is studied using the polygonal ellipsometry method. A combined approach is proposed to analyze the angular ellipsometry data for the parameters $\psi$ and $\Delta$. It consists in the application of the multilayer medium model and the matrix method, while simulating the propagation of optical radiation in this medium in order to obtain the theoretical angular dependences of $\tan \psi$ and $\cos \Delta$. In this method, the dependence of the sought optical profile on the specimen depth is an additional condition imposed on the multilayer model. Evolutionary numerical methods are used for finding the global minimum of the mean squared error (MSE) between the corresponding theoretical and experimental dependences, and the parameters of an optical profile are determined. A model in which the inner non-oxidized layer of porous silicon is homogeneous, whereas the refractive index in the outer oxidized layer has a linear profile, is analyzed. It is shown that the linear and two-step models for the refractive index of an oxidized film provided the best agreement with the experimental ellipsometric functions. The adequacy of the theoretical model is also confirmed by determining the color coordinates of the specimen.
\end{abstract}

Keywords: Fresnel equations, porous silicon, differential evolution method, the CIELAB color space, color coordinates, color matching functions (CMF), CIE standard illuminant D65.

\section{Introduction}

Porous silicon is obtained by the electrochemical etching of single-crystalline silicon in a specially selected electrolyte prepared on the basis on the aqueous solution of hydrofluoric acid. As a result of electrochemical reactions occurring in the silicon bulk, there arises a region near the silicon surface with a branched system of pores. The latter are mainly oriented along the current direction and, most often, perpendicularly to the specimen surface. The thickness of this region depends on the technological conditions of porous silicon manufacture and amounts to a few micrometers [1-3].

After the current has been switched off, the specimen is brought into the air environment. Chemical reactions in the formed porous silicon layer fade, which is accompanied by the interaction with atmospheric oxygen and water vapor. After several months of the specimen storage in air, a thin film with a

(C) O.I. ZAVALISTYI, O.V. MAKARENKO,

V.A. ODARYCH, A.L. YAMPOLSKIY, 2020

ISSN 2071-0194. Ukr. J. Phys. 2020. Vol. 65, No. 1 thickness of up to two hundred nanometers emerges on the porous silicon surface. This film may contain pore remnants (the silicon frame) that are partially or completely filled with reaction products; the latter are mainly silicon oxides of various compositions. There are spectro-ellipsometric data that show that this film is not homogeneous across its thickness [4], but may be composed of two components [5].

Spectro-ellipsometric measurements [1-3] testify to a complicated multilayered structure of porous silicon. However, it is unclear which object those data are related to: the near-surface layer or the deposited film. The aim of this work is to study the structure of the emerging film and to determine its optical parameters in the framework of the most general model, which makes allowance for the inhomogeneity of the researched object over its depth. The study of porous silicon is a challenging task in view of the application of this silicon form to the creation of sensors and polarization elements, as well as to biology and medicine [6]. 


\section{Experimental Part}

A specimen of porous silicon fabricated in the form of a plate about $1 \mathrm{~mm}$ in thickness was studied. The specimen was obtained by the electrochemical etching of single-crystalline silicon of the $p$-type for $3 \mathrm{~min}$ under a current density of $10 \mathrm{~mA} / \mathrm{cm}^{2}$ in the electrolyte $\mathrm{HF}+$ acetone taken in a volume ratio of $2: 1$. After the manufacture, the specimen had been stored in the laboratory for several years at room temperature and in contact with ambient air. A bright interference pattern in the form of several multicolored stripes (Fig. 1) could be visually observed on the specimen surface, which evidenced the appearance of a thin film with geometrically flat boundaries on the surface of porous silicon itself.

With the help of an automated goniopolarimetric installation [7] and by appying the rotating-analyzer method, angular ellipsometric measurements were carried out. The results obtained are used to determine the following ellipsometric parameters of reflected light: $\Delta$ is the phase difference between the $p$ - and $s$-components of the electric vector of the light wave, and $\psi$ is the arctangent of the ratio between the reflectances in the $p$ - and $s$-planes of the specimen. The source radiation wavelength was $\lambda=625 \mathrm{~nm}$, the spectral half-width $\Delta \lambda=10 \mathrm{~nm}$, the angle of incidence was varied in the interval $\theta=(40 \div 80)^{\circ}$ with a step of $2.5^{\circ}$. The probe point is shown in Fig. 1.

\section{Experimental Ellipsometric Data and Their Discussion}

The obtained ellipsometric data were analyzed in order to solve the inverse problem of ellipsometry, i.e., to determine the characteristics of the reflection sys-

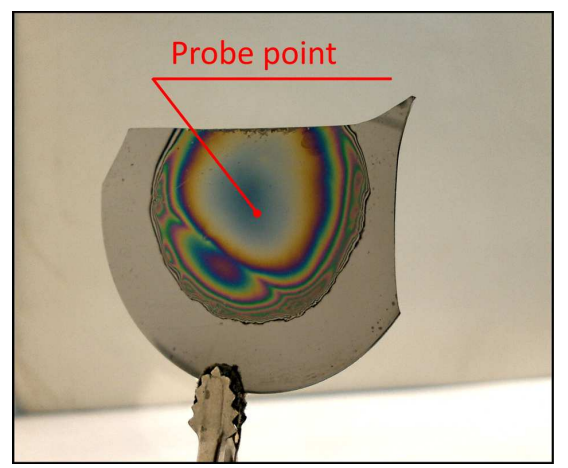

Fig. 1. Porous silicon specimen tem on the basis of the measured values obtained for the ellipsometric parameters. This task was realized using an automated program based on an ellipsometric function obtained for a large number of layers. The examined object was considered as a set of thin plane-parallel layers on a substrate. Every layer was characterized by a complex refractive index $N_{j}=n_{j}-i k_{j}$. All layers were identical in the thickness $d$. In order to calculate the light transmission (reflection and transmission) through this model system, the matrix method was applied. It is based on the electromagnetic radiation theory [8] and continues to be successfully used in a number of problems [9]. One of its advantages consists in making allowance for interference phenomena in multilayered systems.

The $E_{0-}^{(r)}$ waves reflected from such a system in the cases of $p$ - and $s$-polarizations are calculated using the Fresnel equations for the reflection coefficients between the layers. Having expressions for those waves, it is easy to obtain the following ellipsometric parameters:

the amplitude ratio between the reflected wave components,

$\tan \psi=\left|\frac{\left(E_{0-}^{(r)}\right)_{p}}{\left(E_{0-}^{(r)}\right)_{s}}\right|$

and the cosine of a phase shift between them,

$\cos \Delta=\cos \left(\pi-\left|\arg \left[\frac{\left(E_{0-}^{(r)}\right)_{p}}{\left(E_{0-}^{(r)}\right)_{s}}\right]\right|\right)$.

In such a way, we theoretically calculated the dependences of the quantities $\tan \psi$ and $\cos \Delta$ on the incidence angle $\theta$ and compared them with the experimentally measured ones. As a criterion that characterizes the quality of matching between the indicated dependences, we selected the mean square error (MSE) function:

$$
\begin{aligned}
& \text { MSE }=\frac{1}{M} \sum_{j=1}^{M}\left[\left(\cos \left(\Delta_{j}\right)^{\text {theor }}-\cos \left(\Delta_{j}\right)^{\exp }\right)^{2}+\right. \\
& \left.+\left(\tan \left(\psi_{j}\right)^{\text {theor }}-\tan \left(\psi_{j}\right)^{\exp }\right)^{2}\right]
\end{aligned}
$$

where $M$ is the number of experimental points (the angles of incidence). By varying the layer parameters 
Table 1. Thicknesses $\boldsymbol{d}$ and refractive indices $\boldsymbol{n}$ for the first and second layers, and color characteristics $x, y, \Delta E_{a b}^{*}$ obtained within of the two-layer homogeneous model (a)

\begin{tabular}{|c|c|c|c|c|c|c|c|c|}
\hline $\begin{array}{c}\text { Solution } \\
\text { No. }\end{array}$ & $d_{1}, \mathrm{~nm}$ & $n_{1}$ & $d_{2}, \mathrm{~nm}$ & $n_{2}$ & $\mathrm{MSE}, \times 10^{-3}$ & $x$ & $y$ & $\Delta E_{a b}^{*}$ \\
\hline 1 & 46.3 & 1.507 & 2157.0 & 3.531 & 4.84 & 0.266 & 0.298 & 6.0 \\
\hline 2 & 148.1 & 1.496 & 1994.8 & 3.495 & 4.85 & 0.267 & .299 & 5.6 \\
\hline 3 & 149.1 & 1.489 & 1913.8 & 3.475 & 4.88 & 0.268 & 0.300 & 5.2 \\
\hline 4 & 144.7 & 1.517 & 2319.3 & 3.561 & 4.89 & 0.265 & 0.297 & 6.2 \\
\hline 5 & 144.1 & 1.521 & 2400.4 & 3.574 & 4.93 & 0.264 & 0.297 & 6.4 \\
\hline 6 & 143.4 & 1.525 & 2481.6 & 3.587 & 4.98 & 0.264 & 0.296 & 6.5 \\
\hline 7 & 142.8 & 1.529 & 2562.6 & 3.599 & 5.03 & 0.264 & 0.296 & 6.7 \\
\hline 8 & 142.3 & 1.533 & 2643.8 & 3.610 & 5.10 & 0.263 & 0.296 & 6.8 \\
\hline 9 & 152.8 & 1.467 & 1670.9 & 3.403 & 5.12 & 0.270 & 0.302 & 4.8 \\
\hline 10 & 139.9 & 1.548 & 3049.3 & 3.657 & 5.50 & 0.262 & 0.294 & 7.3 \\
\hline
\end{tabular}

of the model in order to minimize the MSE value, the optical characteristics of a specimen can be determined. For this purpose, we wrote a program in the LabVIEW environment, which minimized the MSE considered as a function of many variables. Besides the simplest theoretical models, such as a semiinfinite medium or one- and two-layer models, this program allowed more sophisticated optical profiles to be analyzed. For this purpose, the number of layers in the model was taken to be equal to 500. Surely, for such a large number of parameters, the problem could not be solved absolutely exactly. Therefore, the refractive indices of all layers were related among themselves by means of a given functional dependence (for example, linear), which describes a certain type of optical profiles.

At the first stage, a two-layer homogeneous model was used to describe the specimen. A homogeneous layer of porous silicon was assumed to be located immediately on the silicon surface. In turn, this layer was assumed to be covered with a homogeneous oxidized layer (Fig. 2, a). In the course of simulation, the variation interval for the refractive index of the upper (oxidized) layer was taken to equal $n_{1}=1.0 \div 2.0$, and the corresponding interval for its thickness to $d_{1}=1 \div 400 \mathrm{~nm}$. For porous silicon (the intermediate layer), the relevant intervals were $n_{2}=1.6 \div 3.9$ and $d_{2}=1 \div 4 \mu \mathrm{m}$, respectively. The refractive index of the substrate was taken to be fixed and equal to $n_{3}=3.97$, which corresponded to single-crystalline silicon. The absorption indices $\left(\kappa_{3}=0.03\right.$ for single-crystalline silicon) were
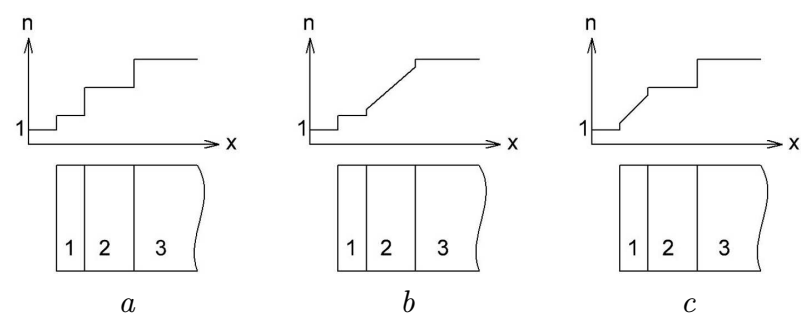

Fig. 2. Two-layer models for the optical profile in the specimen: $(a)$ with homogeneous layers, $(b)$ and $(c)$ with a linearly changing refractive index

neglected by taking them approximately equal to zero.

The relief of the MSE goal function is very complcated. In particular, it can possess plenty of local minima. Therefore, its global minimum was found using the differential evolution method [10]. The advantages of the latter include the simplicity of its implementation and a small number of control parameters. The starting point of the algorithm was randomly selected within the selected limits, and the MSE minimization procedure was repeated many times. As a result, 20 sets of solutions (the thicknesses $d_{j}$ and the refractive indices $n_{j}$ of the layers) were obtained, which turned out to be rather close to each other. They were sorted according to the MSE value, the best ten of them were selected for the further analysis, and the others were rejected (see Table 1).

When studying the structure of thin layers, the spectral ellipsometry is, as a rule, more informative than the angular one. Although the correspond- 


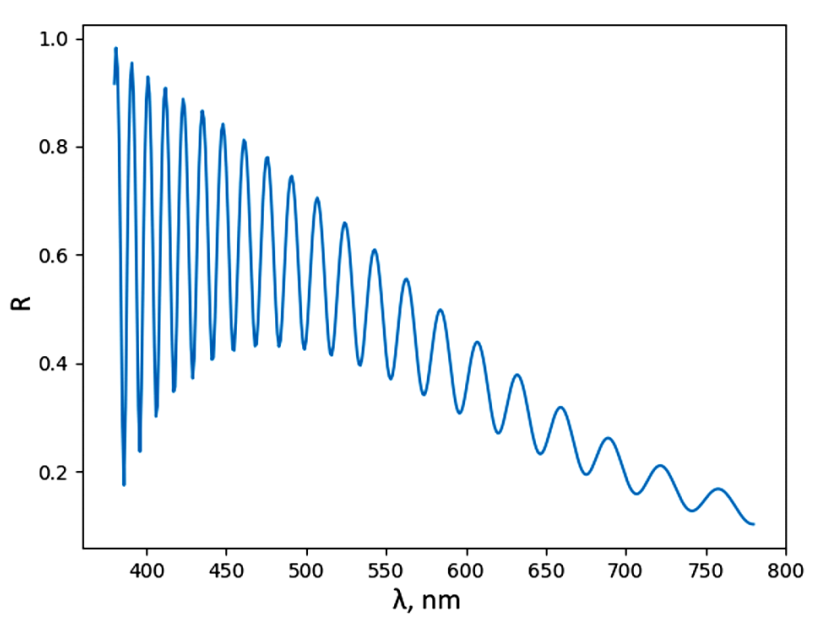

Fig. 3. Reflection spectrum $R(\lambda)$ of porous silicon calculated for solution No. 1 of the homogeneous theoretical model $(a)$

ing measurements were not carried out in this work, the following trick was applied instead. The examined specimen had a pronounced interference pattern on its surface (see Fig. 1). Therefore, colorimetry methods could be used to additionally evaluate the adequacy of the applied theoretical models and the results obtained. By varying the wavelength $\lambda$, - this is one of the parameters of the theoretical model the light reflection spectrum at the normal incidence, $R(\lambda)$, was calculated for each solution. A typical form of those spectra is shown in Fig. 3. Knowing $R(\lambda)$, the color coordinates of the specimen in the system $x y Y$

Table 2. Thickness $\boldsymbol{d}_{2}$ is the variation interval of the refractive indices $n_{21}$ and $n_{22}$ for the intermediate layer of porous silicon obtained in the linear approximation (b) for the refractive index

\begin{tabular}{|c|c|c|c|c|}
\hline $\begin{array}{c}\text { Solution } \\
\text { No. }\end{array}$ & $d_{2}, \mathrm{~nm}$ & $n_{21}$ & $n_{22}$ & MSE, $\times 10$ \\
\hline 1 & 2427.9 & 3.535 & 3.536 & 5.09 \\
2 & 2727.0 & 3.505 & 3.506 & 6.45 \\
3 & 2466.6 & 3.483 & 3.484 & 5.79 \\
4 & 2048.7 & 3.558 & 3.558 & 4.98 \\
5 & 2221.2 & 3.572 & 3.572 & 4.92 \\
6 & 2482.3 & 3.586 & 3.586 & 4.98 \\
7 & 2206.0 & 3.596 & 3.596 & 5.05 \\
8 & 3264.6 & 3.615 & 3.615 & 6.20 \\
9 & 2141.1 & 3.412 & 3.413 & 5.75 \\
10 & 3050.5 & 3.655 & 3.656 & 5.50 \\
\hline
\end{tabular}

were calculated using the standard procedure [11]:

$x=\frac{X}{X+Y+Z}, \quad y=\frac{Y}{X+Y+Z}$,

where

$X=k \int S(\lambda) R(\lambda) \bar{x}(\lambda) d \lambda$,

$Y=k \int S(\lambda) R(\lambda) \bar{y}(\lambda) d \lambda$,

$Z=k \int S(\lambda) R(\lambda) \bar{z}(\lambda) d \lambda$

$S(\lambda)$ is the spectral distribution of the radiation power emitted by a standard illuminant (for getting daylight, this is a CIE standard illuminant D65); $\bar{x}(\lambda), \bar{y}(\lambda)$, and $\bar{z}(\lambda)$ are the color matching functions; and $k$ is the normalization constant. The integration is carried out over the whole visible spectral interval.

The calculated color coordinates were compared with their counterparts obtained using the photographic method in the probe region $(x=0.272$, $y=0.313)$. The distance $\Delta E_{a b}^{*}$ in the CIELAB color space [11], which shows how close two colors are to each other, was chosen as a matching criterion. In order to determine this distance, we have to change to the corresponding coordinate frame. Then

$\Delta E_{a b}^{*}=\sqrt{\left(\Delta L^{*}\right)^{2}+\left(\Delta a^{*}\right)^{2}+\left(\Delta b^{*}\right)^{2}}$.

The values of the indicated colorimetric quantitiesare also quoted in Table 1. They correspond to the visually observed blue color of the specimen in the probe area. This comparison confirms that the two-layer homogeneous model describes the optical properties of the porous silicon specimen rather accurately (the conventional color resolution threshold equals 4). However, one should not forget that different reflectance spectra may correspond to the same color. Therefore, the described colorimetric approach is only an additional testing method.

The total pore depth mainly depends on the etching time of a specimen. The sum of the obtained thicknesses $d_{1}+d_{2} \approx 2.5 \mu \mathrm{m}$ agrees well with the literature data obtained after the about 3-min etching of a specimen [1-3]. However, in reality, the structure of layers can be inhomogeneous, so that the additional testing is required. As was marked above, in order to 
Table 3. Thicknesses $\boldsymbol{d}$ and refractive indices $\boldsymbol{n}$ of the first and second layers, and color characteristics $x, y, \Delta E_{a b}^{*}$ obtained in the linear model (c) for the outer layer (film)

\begin{tabular}{|c|c|c|c|c|c|c|c|}
\hline $\begin{array}{c}\text { Solution } \\
\text { No. }\end{array}$ & $d, \mathrm{~nm}$ & $n_{11}$ & $n_{12}$ & $\mathrm{MSE}, \times 10^{-3}$ & $x$ & $y$ & $\Delta E_{a b}^{*}$ \\
\hline 1 & 149.8 & 1.464 & 1.550 & 4.67 & 0.268 & 0.301 & 4.8 \\
\hline 2 & 151.5 & 1.455 & 1.537 & 4.68 & 0.269 & 0.302 & 4.5 \\
\hline 3 & 152.6 & 1.449 & 1.530 & 4.71 & 0.270 & 0.303 & 4.2 \\
\hline 4 & 148.3 & 1.472 & 1.562 & 4.71 & 0.267 & 0.300 & 5.1 \\
\hline 5 & 147.7 & 1.475 & 1.568 & 4.75 & 0.267 & 0.300 & 5.2 \\
\hline 6 & 147.2 & 1.477 & 1.574 & 4.78 & 0.266 & 0.300 & 5.3 \\
\hline 7 & 146.6 & 1.480 & 1.579 & 4.84 & 0.266 & 0.299 & 5.4 \\
\hline 8 & 146.2 & 1.481 & 1.585 & 4.89 & 0.266 & 0.299 & 5.5 \\
\hline 9 & 156.5 & 1.427 & 1.507 & 4.93 & 0.272 & 0.305 & 3.8 \\
\hline 10 & 144.4 & 1.487 & 1.610 & 5.22 & 0.264 & 0.298 & 5.9 \\
\hline
\end{tabular}

obtain a correct solution of the inverse ellipsometric problem, the expected optical profile of the specimen has to be described by a certain function.

Let us assume the upper layer of the system to be homogeneous and fix its parameters $n$ and $d$ at the valuesobtained for one of the solutions at the previous simulation stage. At the same time, the intermediate layer is considered to be inhomogeneous, i.e., with a certain distribution of the refractive index $n$ over the depth. A linear profile was chosen, as the simplest one, to simulate the layer inhomogeneity (in Fig. 2, b, the refractive index varies from $n_{21}$ to $n_{22}$ ). Optimal parameters for the intermediate layer were found using the described procedure for each of 10 previously selected solutions. The results obtained are summarized in Table 2.

When analyzing the layer parameters and the MSE values obtained in the framework of the homogeneous model, one can see two trends. First, the thickness $d_{2}$ of the intermediate layer is by $10 \%$, on average, larger in the inhomogeneous layer model than in the homogeneous one. This is also true for the corresponding MSE values. Second, the slope of a linear distribution turns out to be very small, so that the model becomes actually degenerate into the case of homogeneous layer. From whence, a conclusion can be drawn about the probable uniformity of the refractive index $n_{2}$ in the intermediate layer across its depth.

Now, let us suppose that the upper layer is inhomogeneous (Fig. 2,c), and its refractive index varies linearly from $n_{11}$ to $n_{12}$. We fix the parameters ob- tained for the intermediate layer in the homogeneous model and perform the same calculations for those 10 solutions. New results are summarized in Table 3. As one see, there is a dependence of the refractive index in the upper layer on the depth; it varies, on average, from $n_{11}=1.47$ to $n_{12}=1.56$. The thicknesses of the oxidized layer calculated in the inhomogeneous and homogeneous models are approximately identical (to an accuracy of $2 \%$ ), and the MSE decreases by approximately $4 \%$.

Analogously to what was done for the homogeneous model $(a)$, the reflection spectra $R(\lambda)$, the color coordinates $(x, y)$ of the specimen, and their difference from the observed color in the $L^{*} a^{*} b^{*}$ space were calculated. In comparison with the homogeneous model, this difference was smaller, which confirmed the adequacy of the results obtained.

Finally, the upper oxidized layer was divided, in the theoretical model, into two homogeneous layers (the three-layer model $(d)$ ). In this case, the first of them could describe a possible result of the interaction of the residual reaction products at their contact with atmospheric air. The parameters of the oxidized porous silicon layer were fixed (see Table 1). At this stage, the calculations were performed only for the first 5 solutions, and their results are shown in Table 4.

It is evident that the outer film layer has a larger thickness, $d_{0}$, than the inner layer, $d_{1}$, and their sums are equal to the previously obtained thicknesses of the oxidized layer, $d_{1}$, with an accuracy of $1 \%$. The corresponding average refractive indices are $n_{0}=1.50$ 

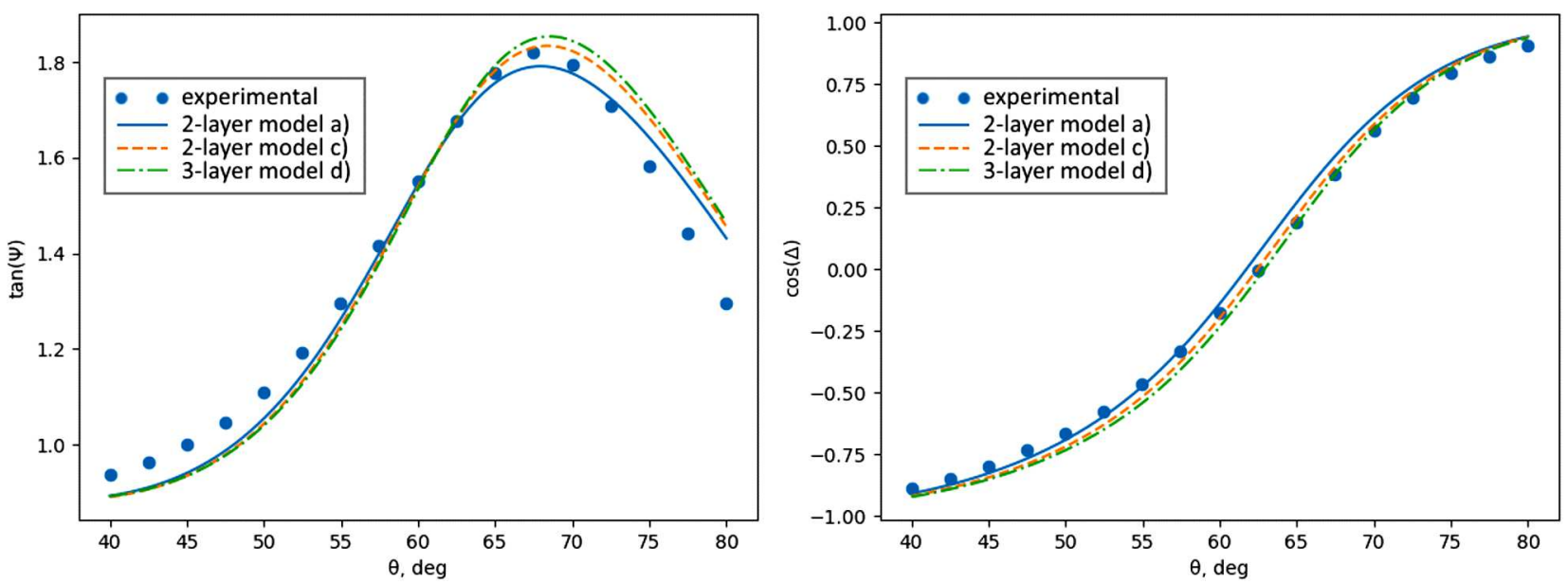

Fig. 4. Experimental (symbols) and theoretical (curves) dependences of the quantities tan $\psi$ and cos $\Delta$ on the incidence angle $\theta$ calculated for solution No. 1 in the framework of theoretical models $(a),(c)$, and $(d)$

Table 4. Thicknesses $\boldsymbol{d}$, refractive indices $\boldsymbol{n}$, and color characteristics $x, y, \Delta E_{a b}^{*}$ of an oxidized film obtained in the framework of the three-layer model (d)

\begin{tabular}{|c|c|c|c|c|c|c|c|c|}
\hline $\begin{array}{c}\text { Solution } \\
\text { No. }\end{array}$ & $d_{0}, \mathrm{~nm}$ & $n_{0}$ & $d_{1}, \mathrm{~nm}$ & $n_{1}$ & $\mathrm{MSE}, \times 10^{-3}$ & $x$ & $y$ & $\Delta E_{a b}^{*}$ \\
\hline 1 & 128.5 & 1.505 & 19.1 & 1.674 & 4.28 & 0.267 & 0.300 & 5.4 \\
\hline 2 & 130.1 & 1.493 & 19.3 & 1.653 & 4.31 & 0.268 & 0.301 & 5.1 \\
\hline 3 & 131.0 & 1.487 & 19.4 & 1.642 & 4.34 & 0.269 & 0.302 & 4.7 \\
\hline 4 & 127.0 & 1.514 & 19.2 & 1.693 & 4.30 & 0.266 & 0.299 & 5.6 \\
\hline 5 & 126.2 & 1.518 & 19.3 & 1.702 & 4.31 & 0.265 & 0.298 & 5.8 \\
\hline
\end{tabular}

and $n_{1}=1.67$. The MSE decreases by $9 \%$ as compared with the previous model, but $\Delta E_{a b}^{*}$ increased by $12 \%$. On the whole, we may say that this extended three-layer model describes the ellipsometric results of measurements in the best way in comparison with the previous models.

An illustrative example demonstrating the validity of the applied theoretical approach is the forms of the experimental ellipsometric functions and the ellipsometric functions calculated by minimizing the MSE. The corresponding plots for solution No. 1 are shown in Fig. 4.

The described approach can be applied not only to porous silicon, but also to various dielectric, semiconductor, or metallic materials with an inhomogeneous near-surface region (e.g., optical glass [12]). In the case of conducting media, one cannot neglect the imaginary part of the refractive index, which is included into the theoretical model. The method makes it possible to compare the adequacy of preassigned optical profile models and to determine the best among them. But the specific form of the optical profile for those models should be chosen proceeding from the structural peculiarities in the examined object.

\section{Conclusions}

The near-surface region in real porous silicon has a complicated structure. This region can be resolved into porous silicon located on a substrate of singlecrystalline silicon and an upper oxidized layer. The upper layer (the film) is a result of the interaction between the electrochemical reaction products and atmospheric air, whereas the inner part is porous silicon itself formed at the moment of the current switching off. Its pores are filled with the products of electrochemical reactions, which have no access to atmospheric air.

ISSN 2071-0194. Ukr. J. Phys. 2020. Vol. 65, No. 1 
The optical properties of porous silicon are well described in the framework of the two-layer model. The total thickness of porous silicon (about $2.5 \mu \mathrm{m}$ ) is in good agreement with the literature data corresponding to the manufacture technology for this specimen. However, it is more probable that the deep layer of porous silicon is homogeneous across its thickness, whereas the near-surface oxidized layer has a more complicated distribution of the refractive index. Both linear and two-step profiles are suitable for its description.

The values obtained for the refractive indices of near-surface layers in porous silicon testify that the composition of those layers includes silicon oxides (with a refractive index close to 1.45), the remnants of non-oxidized silicon with a refractive index of about 3.9 (the access to them is blocked by oxides), and empty pores.

Porous silicon is characterized by a pronounced interference in the surface layer. This phenomenon can be used to additionally estimate the porous silicon thickness, which was found to equal about $150 \mathrm{~nm}$. The applied colorimetry methods demonstrate good agreement between the calculated and measured colors of the specimen, which confirms the adequacy of simulation results.

1. T. Lohner, D.J. Wentink, E. Varsonyi, M. Fried. In Proceeding of the 2nd Japan-Central Europe Joint Workshop "Modeling of Materials and Combustion" (Budapest, November 7-9, 1996). Edited by I. Vajda (Technical University of Budapest, 1997), p. 66.

2. M. Fried, T. Lohner, O. Polgar, P. Petric, E. Vazsonyi, I. Barsony, J.P. Piel, J. L. Stehle. Characterization of different porous silicon structures by spectroscopic ellipsometry. Thin Solid Films 276, 223 (1996).

3. C. Robert, L. Bideux, B. Gruzza, M. Cadoret, T. Lohner, M. Fried, E. Vazsonyi, G. Gergely. Spectroellipsometry and electron spectroscopy of porous $\mathrm{Si}$ thin films on $\mathrm{p}^{+}$substrates. Thin Solid Films 317, 210 (1998).

4. V.A. Makara, V.A. Odarych, O.V. Vakulenko, O.I. Dacenco. Ellipsometric studies of porous silicon. Thin Solid Films 342, 230 (1999).

5. V.A. Odarych. Applied Photometric Ellipsometry ("Pulsary" Kyiv Univ. Publ., 2017) (in Ukrainian).

6. Porous Silicon: From Formation to Application. Vol. 2: Biomedical and Sensor Applications. Edited by G. Korotcenkov (Taylor and Francis Group, 2016).
7. A.L. Yampolskiy, O.V. Makarenko, L.V. Poperenko, V.O. Lysiuk. Ellipsometry of hybrid noble metal-dielectric nanostructures. Semicond. Phys. Quant. Electron. Optoelectron. 21, 412 (2018).

8. P.H. Berning. Theory and calculations of optical thin films. In Physics of Thin Films, Vol. 1. Edited by G. Hass (Academic Press, 1963), p. 69.

9. L.N. Acquaroli. Matrix method for thin film optics. e-print arXiv:1809.07708v1 (2018).

10. R. Storn, K. Price. Differential evolution - a simple and efficient heuristic for global optimization over continuous spaces. J. Glob. Optim. 11, 341 (1997).

11. Colorimetry: Understanding the CIE System. Edited by J. Schanda (Wiley, 2007).

12. O.V. Makarenko, L.V. Poperenko, O.I. Zavalistyi, A.L. Yampolskiy. Ellipsometric diagnostics of a transient surface layer in optical glass. Ukr. J. Phys. 64, 442 (2019).

Received 25.05.19.

Translated from Ukrainian by O.I. Voitenko

О.І. Завалістий, О.В. Макаренко,

В.А. Одарич, А.Л. Ямполъсъжий

СТРУКТУРА ОКИСНОЇ ПЛІВКИ

НА ПОВЕРХНІ ПОРУВАТОГО КРЕМНІЮ

Р е $з$ ю м е

Тривале перебування поруватого кремнію на повітрі приводить до зміни структури його приповерхневого шару, для опису якого стандартна одношарова модель вже не є достатньо точною. Методом багатокутової еліпсометрії досліджено структуру поверхневого шару поруватого кремнію. Запропоновано комбінований підхід до аналізу даних кутової еліпсометрії, який полягає в застосуванні моделі багатошарового середовища і матричного методу розрахунку поширення оптичного випромінювання у ньому для одержання теоретичних кутових залежностей $\tan \psi$ та $\cos \Delta$. При цьому вид функції шуканого оптичного профілю за глибиною є додатковою умовою, яка накладається на багатошарову модель. Еволюційними чисельними методами проведено пошук глобального мінімуму функції середньоквадратичного відхилення MSE (Mean Squared Error) між теоретичними та експериментальними залежностями і одержано параметри оптичного профілю. Проаналізована модель, згідно з якою глибинний неокислений шар поруватого кремнію є однорідним, а зовнішній окислений шар має лінійний профіль показника заломлення. Показано, що лінійна та двоступінчата моделі окисленої плівки дають найкраще узгодження з експериментальними еліпсометричними функціями. Адекватність теоретичної моделі підтверджено також шляхом визначення координат колірності зразка. 